\title{
Quantitative Photodeprotection Assessment of Caged Resveratrol by Fluorescence Measurement
}

\author{
Shin Hikage, Yasuhiro Nishiyama,*당 Yasuo Sasaki, Hiroki Tanimoto, Tsumoru Morimoto, \\ and Kiyomi Kakiuchi*
}

Graduate School of Materials and Science, Nara Institute of Science and Technology (NAIST), 8916-5 Takayama-cho, Ikoma, Nara 630-0101, Japan

\section{Supporting Information}

ABSTRACT: For monitoring the regenerated bioactivity of a masked bioactive compound, resveratrol (a luciferase inhibitor) was selected to target such a compound. Caged resveratrol, masked by thiochromone-type photolabile-protecting groups was synthesized in the study. Each caged resveratrol showed lower bioactivity when compared to that shown by the original molecule. After photoirradiation, the original bioactivity was found to be regenerated. Furthermore, the fluorescent compound derived from the thiochromone-type photolabile-protecting groups was generated simultaneously. A linear correlation was observed between the regenerated bioactivity and generated fluorescence intensity. Thus, we quantitatively monitored the recovered bioactivity successfully by measuring the fluorescence.

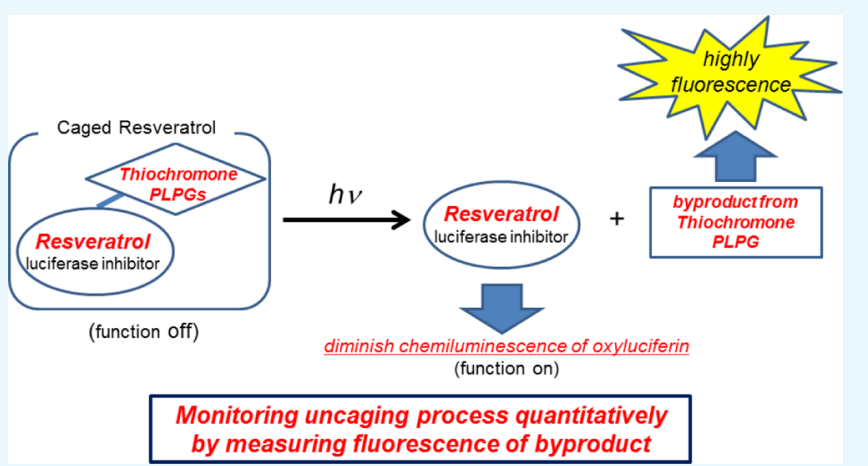

analysis of the compounds. However, real-time assessment of the photodeprotection process has not yet been elucidated.

Our laboratory has reported novel thiochromone-type PLPGs. ${ }^{13-16}$ These PLPGs show a unique property, which is the generation of highly fluorescent compound during photoirradiation (Scheme 1). This property enables the application of quantitative real-time monitoring of the photodeprotection process by just measuring fluorescence (FL) using FL microscopes. Recently, the following thiochromone-type PLPGs have been applied to the caged compounds: caged D-luciferin ${ }^{17}$ and caged nucleic acid. ${ }^{18}$ In the case of caged D-luciferin, regenerative D-luciferin was confirmed via chemiluminescence (CL) measurement of oxyluciferin, derived from the following luciferinluciferase enzyme reaction.

However, this study did not utilize the fluorescent compound derived from thiochromone-type PLPGs for the assessment of the photodeprotection process because the generated luciferin also possesses a strong fluorescent property. In the case of the caged nucleic acid, it was expected that the photodeprotection process could be measured using the fluorescent compound derived from the PLPG, as the nucleic acids possess no fluorescent property. However, in the photodeprotection process of caged nucleic acids, several fluorescent compounds, such as reaction intermediates, were generated. Thus, the photodeprotection process was not monitored quantitatively

Received: March 3, 2017

Accepted: May 11, 2017

Published: May 24, 2017 
Scheme 1. Photodeprotection and Photodeprotection Using Thiochromone-Type PLPG
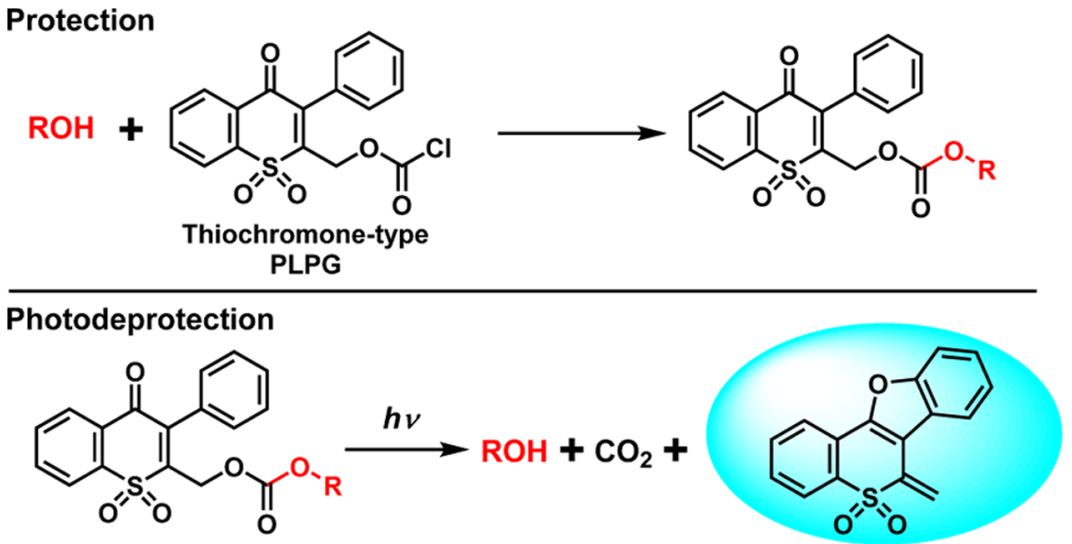

Highly fluorescent compound

Scheme 2. Control of Inhibitory Ability Using Caged Resveratrol (a) without and (b) with Photoirradiation

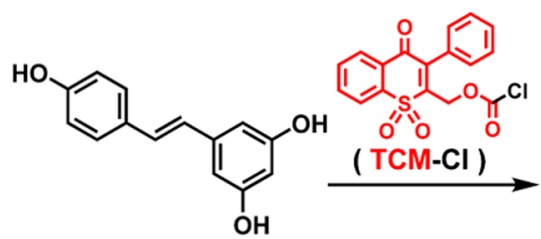

Resveratrol<smiles>COc1ccc(/C=C/c2cc(OC)cc([O+]C)c2)cc1</smiles>

Caged resveratrol

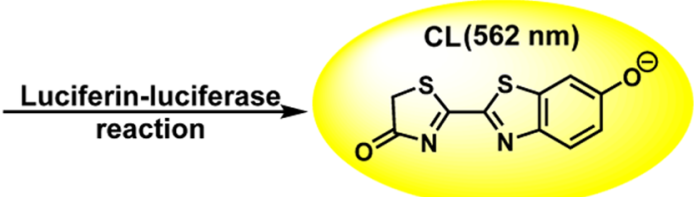

Oxyluciferin<smiles></smiles>

Resveratrol (Inhibition of A)

A )

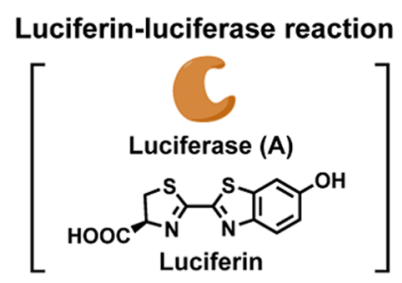

using FL measurement. For quantitative monitoring of the generated bioactivity, both the use of a substrate with no fluorescent property and the generation of only one fluorescent compound after photodeprotection are required. In this work, we aim to monitor directly the recovery of bioactivity by FL of the fluorescent compound derived from the thiochromone-type PLPG.

\section{RESULTS AND DISCUSSION}

To achieve our goal, we selected resveratrol (3,5,4'-trihydroxystilbene) as the new target molecule. Resveratrol does not possess a fluorescent property, and the hydroxyl group of resveratrol can be protected using the carbonate linkage by the thiochromone-type PLPG. In the case of photoirradiation at this linkage, both deprotected compound and fluorescent compound were formed, accompanied by the release of $\mathrm{CO}_{2}$, as reported previously. ${ }^{13}$ Furthermore, the luciferin-luciferase reaction generates the chemiluminescent product oxyluciferin, and resveratrol is known to be an antioxidant or an inhibitor of luciferase. Thus, when resveratrol is present in the luciferinluciferase reaction, it has been reported to insert preferentially into the active site of luciferase. ${ }^{19}$ Consequently, the luciferinluciferase reaction is inhibited and the generation of oxyluciferin diminishes. However, the size of the caged resveratrol masked by the PLPG is quite large because of the bulkiness of the protecting groups (Scheme 2a). The caged resveratrol, therefore, cannot insert into the active site of luciferase because of steric hindrance. As a result, CL of oxyluciferin must be observed as usual. After photoirradiation of the caged resveratrol, the resveratrol is released from the caged resveratrol, and it is expected that this released resveratrol inhibits the generation of oxyluciferin (Scheme 2b). Furthermore, the highly fluorescent compound is generated simultaneously. ${ }^{13}$ Thus, we expect that the recovery of bioactivity can be quantitatively monitored via FL measurements.

Synthesis and Evaluation of the Inhibitory Ability of Each Caged Resveratrol. As shown in Scheme 3, resveratrol (1) has three hydroxyl groups. Thiochromone-type PLPG (chloroformate thiochromone $S, S$-dioxide) may be connected to each hydroxyl group of $\mathbf{1}$ (one unit: 2, 3; two units: 4; three units: 5). III-Caged resveratrol (5) protecting all hydroxyl groups was synthesized at a moderate yield (33\%). The number of introduced thiochromone-type PLPGs for I- or II-caged resveratrols was controlled by the equivalent of chloroformate thiochromone $S, S$-dioxide. I-Caged resveratrols as orange and yellow solids ( 2 and 3; protected at the meta-position (17\%) and at the para-position (19\%), respectively) were obtained as a 
Scheme 3. Synthesis and Structure of Each Caged Resveratrol

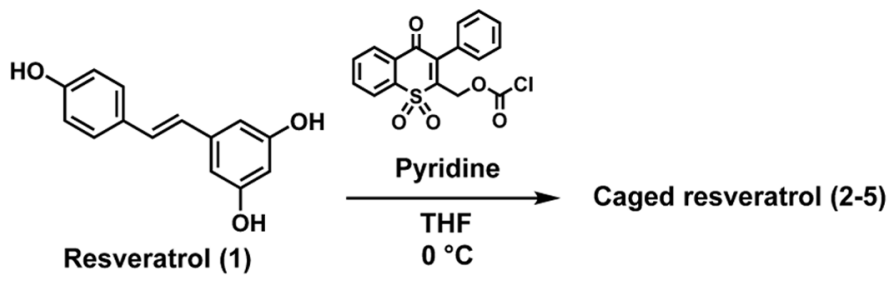<smiles>O=C(OCC1=C(c2ccccc2)C(=O)c2ccccc2S1(=O)=O)Oc1cc(O)cc(/C=C/c2ccc(O)cc2)c1</smiles>

$m$-l-caged resveratrol (2)<smiles>O=C(OCC1=C(c2ccccc2)C(=O)c2ccccc2S1(=O)=O)Oc1ccc(/C=C/c2cc(O)cc(O)c2)cc1</smiles>

p-I-caged resveratrol (3)<smiles>O=C(OCC1=C(c2ccccc2)C(=O)c2ccccc2S1(=O)=O)Oc1ccc(/C=C/c2cc(O)cc(OC(=O)OCC3=C(c4ccccc4)C(=O)c4ccccc4S3(=O)=O)c2)cc1</smiles><smiles>Cc1ccc(OC(=O)OCC2=C(c3ccccc3)C(=O)c3ccccc3S2(=O)=O)cc1</smiles><smiles>CO/C(=C/COC(=O)Oc1cc(/C=C/C2=CC=CC2)cc(OCO)c1)c1ccccc1</smiles>

$m, p$-II-caged resveratrol (4)

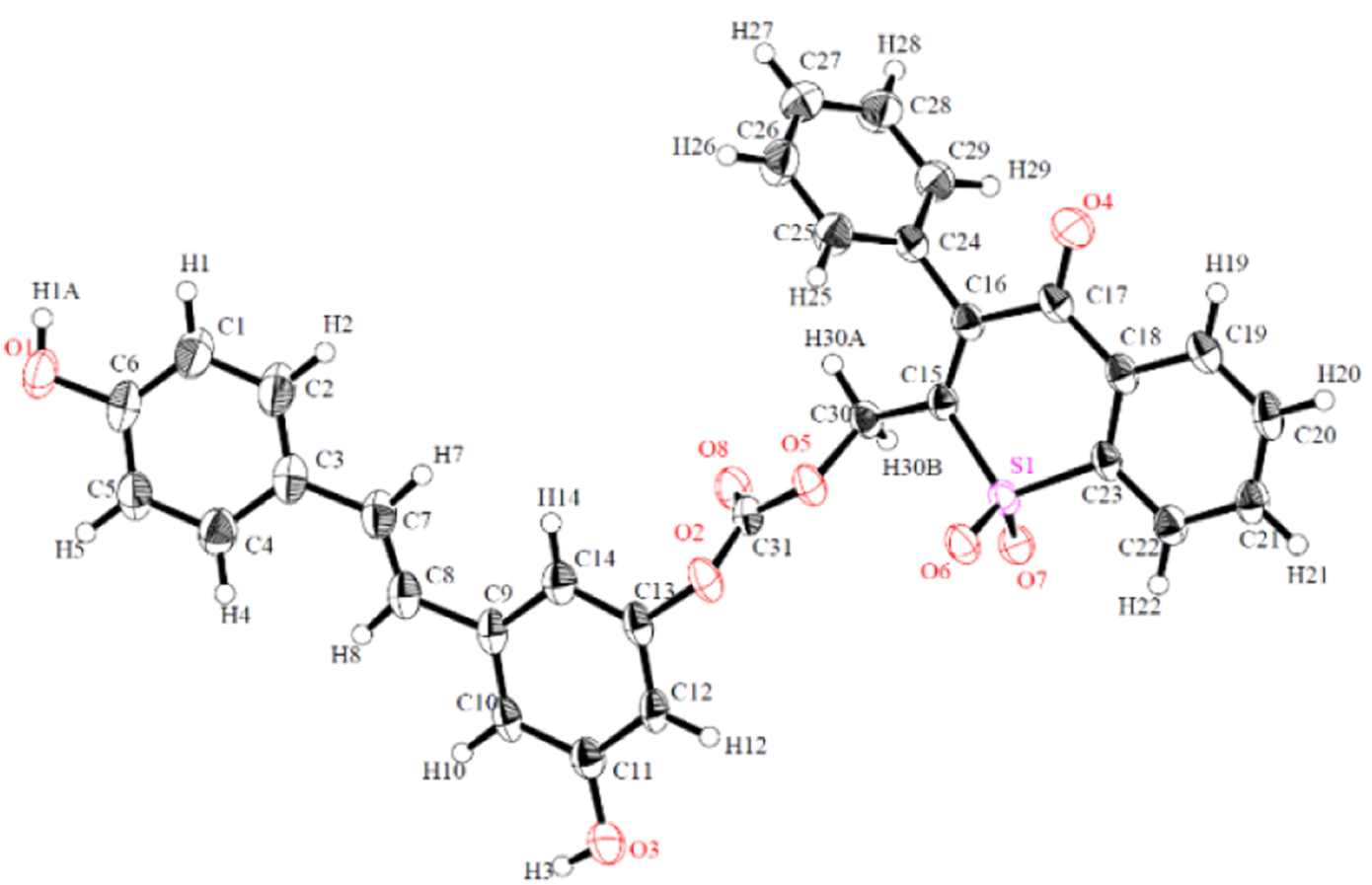

Figure 1. Structure of meta-I-caged resveratrol (2) by X-ray crystal structure analysis.

mixture. The recrystallization of the former solid gave the orange crystal, which was subjected to X-ray crystal structure analysis. This analysis revealed that the orange crystal is a meta-positionmasked 2 (Figure 1). Although recrystallization of the yellow solid was not accomplished, it should be a para-position-masked resveratrol 3, isolated from the mixture of I-caged resveratrols via column chromatography. The synthesis of II-caged resveratrols was also attempted, as in the case of I-caged resveratrols; however, the obtained mixture could not be separated via column chromatography. Thus, we attempted to synthesize the II-caged resveratrol using an alternative method; the $m, p$-II-caged resveratrol (4) was synthesized from 3 as a substrate. Consequently, a moderate amount of the desired compound, 4, was obtained (27\%). 
Then, we examined the luciferase inhibitory ability of the synthesized caged resveratrols (2-5) and the original resveratrol molecule (1), respectively (see Experimental Section). As mentioned before, the chemiluminescent oxyluciferin is generated from the luciferin-luciferase reaction. If resveratrol or caged resveratrols behaved as a luciferase inhibitor, the CL of oxyluciferin would be diminished. Thus, we measured the relative luminescence units (RLUs) of oxyluciferin in the sample containing each (caged) resveratrol (Figure 2). The blank

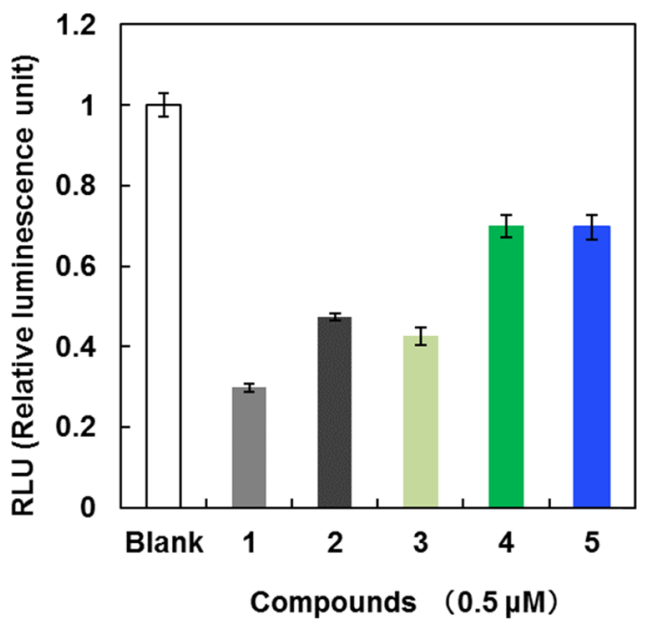

Figure 2. RLU of oxyluciferin containing each compound.

represents the sample containing luciferin and luciferase only. In the experimental sample, oxyluciferin is generated from the normal luciferin-luciferase reaction without inhibition. The RLU obtained in this sample was therefore set as a standard value. The sample of resveratrol 1 presented a very low RLU value. This is because $\mathbf{1}$ shows the natural characteristic as an inhibitor to luciferase. The sample of compound $\mathbf{5}$, which is most bulky among the synthesized caged resveratrols, exhibited a high RLU value. The bulkiness of PLPGs successfully caused the resveratrol to lose its property of a luciferase inhibitor, as we anticipated. The relatively bulky caged compound $\mathbf{4}$ also presented a high RLU value. Both of the thiochromone-type PLPGs introduced aromatic rings to resveratrol (1), causing it to sufficiently lose function as an inhibitor. Thus, the protection of both one meta-position and one para-position is surely important for losing the inhibitory ability. However, the size of the thiochromone-type PLPG would not be sufficient for losing that ability completely.

The RLU values of both the I-caged compound ( 2 and 3 ) samples were lower than those of the II- or III-caged resveratrol (4 and 5) samples, although those values were slightly higher (about 1.3 times) than those of the resveratrol (1) sample. The presence of one thiochromone-type PLPG at either the meta- or para-position rarely affects the function of resveratrol. From these results, we selected $\mathbf{4}$ and $\mathbf{5}$ as the model caged compounds.

Photodeprotection of Caged Resveratrol and Evaluation of Inhibitory Ability. Before the examination of photodeprotection, known as the uncaging process, UV-vis spectra of resveratrol (1) and caged resveratrols (2-5) were recorded to select the appropriate light source for photodeprotection (Figure 3).

Although the end of the absorbance band of resveratrol (1) was at approximately $370 \mathrm{~nm}, \mathbf{4}$ and $\mathbf{5}$ showed absorbance bands at more than $400 \mathrm{~nm}$. From a biochemical point of view, the light

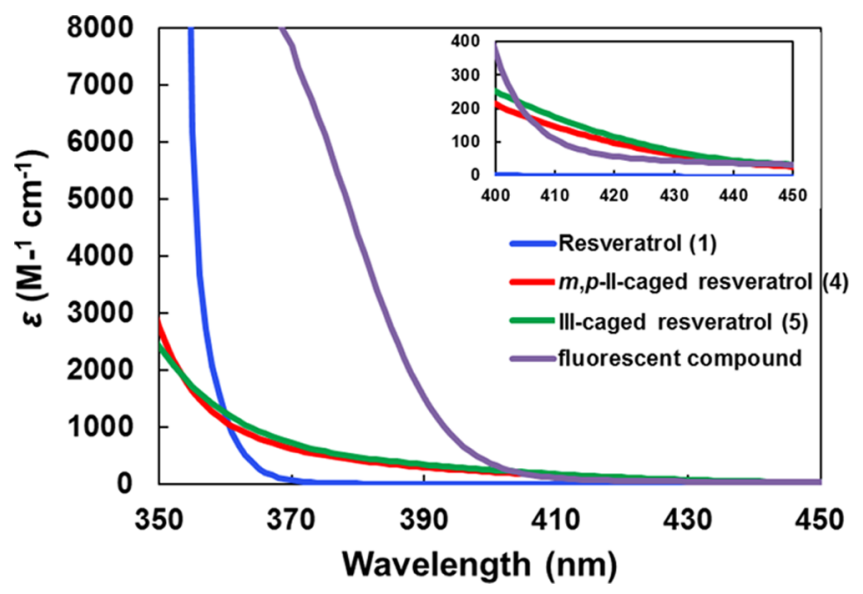

Figure 3. UV-vis spectra of each compound in dimethyl sulfoxide (DMSO).

of a longer wavelength has been preferred for the uncaging process to suppress damage to cell cultures. Furthermore, photoirradiation at wavelengths less than $390 \mathrm{~nm}$ on 1 resulted partially in cis-trans isomerization of the stilbene skeleton. ${ }^{20}$ Hence, we employed a Xe lamp for the irradiation at $420 \mathrm{~nm}$. Uncaging reactions were performed on DMSO (see Experimental Section). If the expected uncaging reaction proceeded, both resveratrol and the fluorescent compound would be generated. To confirm this hypothesis, the FL spectra of the sample solution, after photoirradiation, were first measured at each photoirradiation period. Then, we measured the CL of oxyluciferin in the same sample (see the Experimental Section).

An obvious FL intensity increment accompanied with the photoirradiation time was observed (Figure 4). From the results

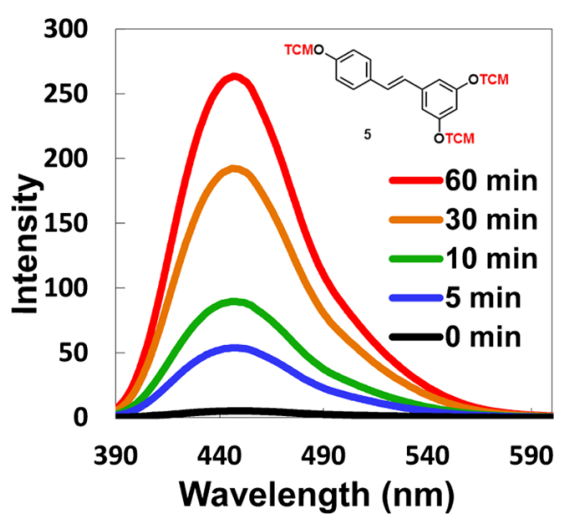

Figure 4. FL spectra of the photodeprotection process (excited at 360 $\mathrm{nm}, 5 \mu \mathrm{M}$ of 5 in DMSO at $0 \mathrm{~min}$ ).

of the mass spectrometry (MS) analysis of one photodeprotection sample and ${ }^{1} \mathrm{H}$ NMR analysis of the total of some experimental solutions, it was verified that the fluorescent compound emitted this FL. This means that the expected uncaging reaction certainly occurs. The RLU value of oxyluciferin in the sample decreased after photoirradiation, as the photoirradiation time increased; however, the degree of decrement was very poor (Figure 5). Even after $60 \mathrm{~min}$ of photoirradiation, the RLU value was considerably higher than that of the original resveratrol, 1. After $60 \mathrm{~min}$ of photoirradiation, the generation of all I-caged ( 2 or 3 ), II-caged ( 4 or $p, p$-substituent compound), and III-caged compounds (5) was 


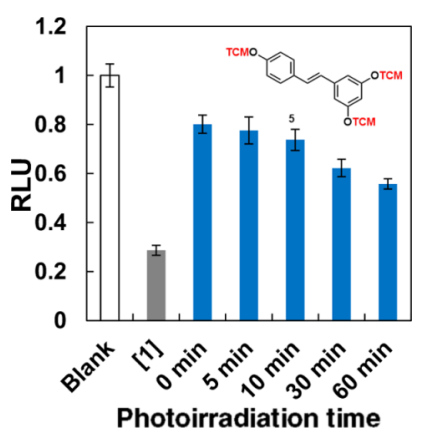

Figure 5. RLU of oxyluciferin in each photodeprotection process of 5 .

confirmed from the electrospray ionization mass spectrometry (ESI-MS) spectra of the sample (see Supporting Information).

In the case of $\mathbf{5}$, all three hydroxyl groups must be removed for the recovery of the original resveratrol, $\mathbf{1}$; however, the generated fluorescent compound also absorbed light at a wavelength of 420 $\mathrm{nm}$. Consequently, the uncaging of 5 was inhibited by the fluorescent compound.

As shown in Figure 2, three groups in $\mathbf{5}$ and two groups in $\mathbf{4}$ possess a similar inhibitory ability to that of luciferase. Thus, photoirradiation of $\mathbf{4}$ was performed to enhance the uncaging efficiency because the removal of the thiochromone-type PLPG in $\mathbf{4}$ proceeds more easily compared to that in $\mathbf{5}$. The smooth increment of the FL intensity of $\mathbf{4}$ as well as photoirradiation time was observed (Figure 6). A FL intensity similar to that in the case

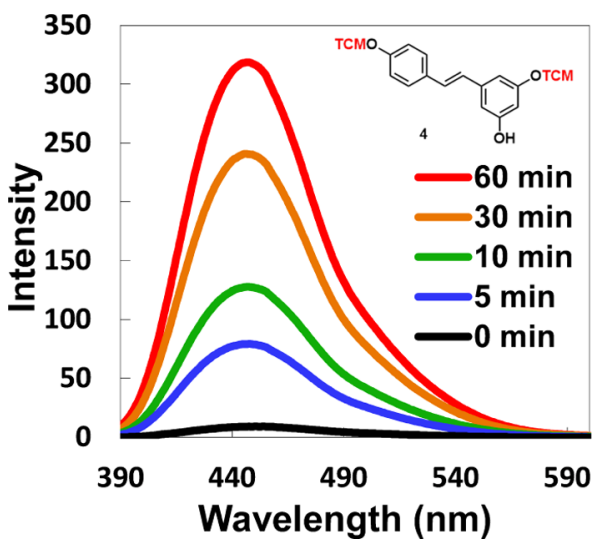

Figure 6. FL spectra of the photodeprotection process (excited at 360 $\mathrm{nm}, 5 \mu \mathrm{M}$ of 4 in DMSO at $0 \mathrm{~min}$ ).

of $\mathbf{5}$ was observed, although there was a lower number of thiochromone-type PLPG (Figure 6 vs Figure 4). The RLU value after $60 \mathrm{~min}$ of photoirradiation was similar to the value for resveratrol. This is because the generated I-caged resveratrols ( 2 and 3 ) from 4 remain in the reaction mixture; however, the RLU value clearly decreased with progress of photodeprotection when compared to that for 5 (Figure 7 vs Figure 5).

These results not only show the efficient photodeprotection reaction of $\mathbf{4}$ but also that the monitoring of photodeprotection by measuring FL achieved what was expected. To discuss these results more quantitatively, we examined the correlation between the increasing rate of the FL intensity of the fluorescent compound and the diminishing rate of the CL intensity.

The correlation between the CL intensity of oxyluciferin and FL intensity of the fluorescent compound is shown in Figure 8. Intrinsically, the uncaging of compound 4 proceeds stepwise, as shown in Scheme 4. Meanwhile, as shown in Figure 2, I-caged

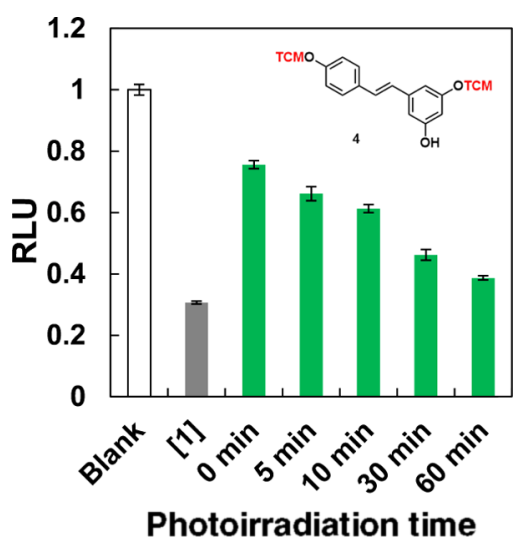

Figure 7. RLU of oxyluciferin in each photodeprotection process of 4.

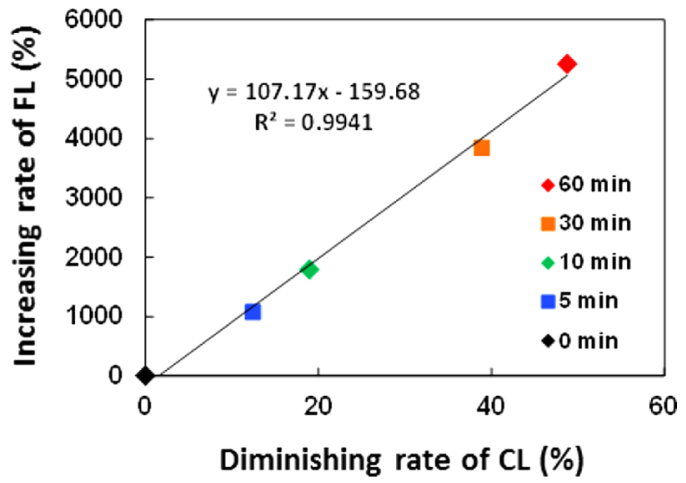

Figure 8. Plot of the increasing rate of FL vs the diminishing rate of CL.

resveratrols 2 and 3 possess an inhibitory ability similar to the original resveratrol $\mathbf{1}$. If both uncaged compounds (one-caged resveratrol, $\mathbf{2}$ or 3 and original resveratrol 1) coexisted in the sample solution, the inflection point (a lower diminishing rate of CL against the increasing rate of FL) would be observed in this correlation. Actually, a good linear correlation was observed over this photoirradiation period (coefficient of determination $\left(R^{2}\right)$ : $0.99)$. This result clearly showed that the first step of the process in Scheme 4 proceeded during this period, and only one-caged resveratrol (irrespective of the substitution position) was contained in sample solution.

Consequently, although regeneration of the original resveratrol from compound $\mathbf{4}$ was not observed, it was demonstrated that the regenerated bioactivity from caged compounds, masked by thiochromone-type PLPGs, was assessed quantitatively by measuring FL, without the other analyses, such as NMR, HPLC, or GC, on the basis of our two strategies (I: the released bioactive compound possesses no fluorescent property, II: one kind of fluorescent compound is afforded after the photoirradiation).

In this study, monitoring of the uncaging process via FL measurement was accomplished in the DMSO solution. However, to apply caged compounds to the in vivo experiment, the uncaging reaction must be conducted under aqueous conditions. Thus, uncaging of the caged resveratrols (4 and 5) was performed under aqueous conditions (DMSO/ $\mathrm{H}_{2} \mathrm{O}$ 50:50). Unfortunately, very low efficiencies of uncaging both compounds were observed under these conditions. This poor result may have been caused by the low water solubility of thiochromone-type PLPGs. Therefore, we will improve the photodeprotection efficiency of new caged compounds under aqueous conditions to modify the structure of the thiochromone-type PLPGs. 
Scheme 4. Photodeprotection of $m, p$-II-Caged Resveratrol

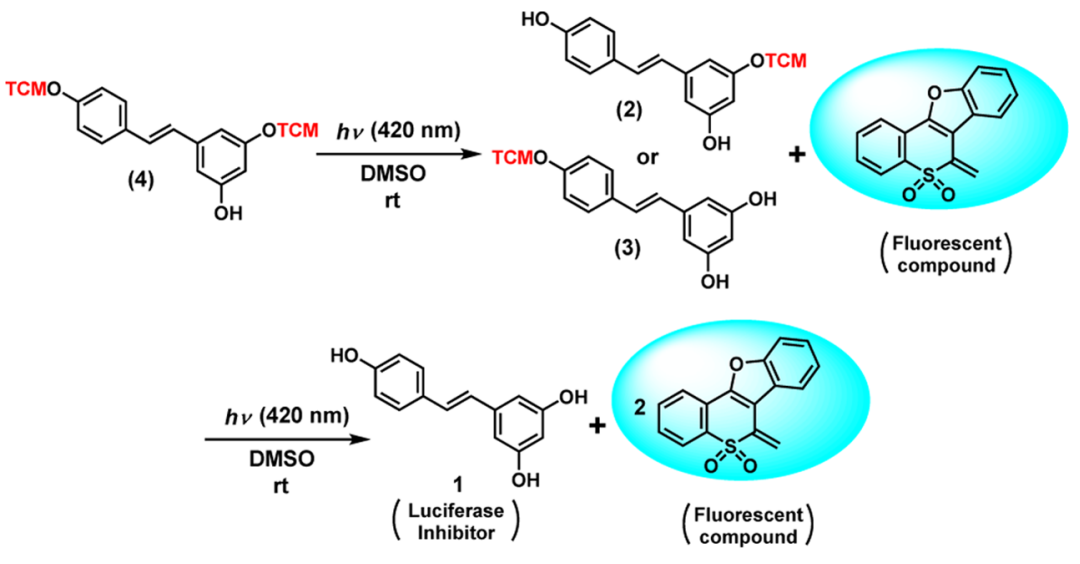

\section{CONCLUSIONS}

To monitor the uncaging process via FL measurements, the novel caged resveratrols, 2-5, which were masked by thiochromone-type PLPGs, were synthesized. The caged resveratrol with thiochromone-type PLPGs (two units or three units) succeeded in lowering the luciferase inhibitory ability of the original resveratrol $\mathbf{1}$. After photoirradiation of the caged resveratrol in DMSO, the CL intensity of oxyluciferin, derived from the luciferin-luciferase reaction, diminished. Therefore, the original inhibitory ability of resveratrol was regenerated. Additionally, the FL intensity of the highly fluorescent compound, which was transformed from the thiochromonetype PLPG during photoirradiation, increased. Furthermore, a good linear correlation was observed between the increasing rate of FL intensity and diminishing rate of CL intensity. According to this linear correlation, we succeeded in quantitatively monitoring the uncaging of caged resveratrol only by measuring FL. Development of hydrophilic thiochromone-type PLPGs is in progress.

\section{EXPERIMENTAL SECTION}

General Procedures. Most air or moisture-sensitive reactions were carried out under a nitrogen atmosphere using the available anhydrous solvents. All reagents and solvents that were commercially purchased were used without further purification. An ATP determination kit was purchased from Life Technologies (Invitrogen). ${ }^{1} \mathrm{H}$ NMR spectra were measured on a JEOL JNM-ECP 500 spectrometer $(500 \mathrm{MHz}) .{ }^{1} \mathrm{H}$ NMR spectra were reported as chemical shifts in parts per million $(\mathrm{ppm})(\delta)$, integration, multiplicity $(\mathrm{s}=$ singlet, $\mathrm{d}=$ doublet, $\mathrm{t}=$ triplet, and $\mathrm{m}=$ multiplet $)$. Chemical shifts were reported in $\mathrm{ppm}$ using the peak of chloroform- $d(\delta=7.26 \mathrm{ppm})$ as an internal standard. ${ }^{13} \mathrm{C}$ NMR spectra were measured on a JNM-ECP 500 spectrometer $(126 \mathrm{MHz})$. Chemical shifts were reported in ppm using the peak of chloroform- $d(\delta=77.16 \mathrm{ppm})$ as an internal standard or the peak of acetone- $d(\delta=29.84$ and $206.26 \mathrm{ppm})$. IR spectra were measured on a JASCO FTIR-420 spectrometer. MS and high-resolution mass spectrometry (HRMS) were recorded on a JEOL JMS-T100LC instrument. UV/vis spectra were recorded in a quartz cell ( $10 \mathrm{~mm}$ thickness) on a JASCO V630 spectrometer. FL spectra were recorded in a quartz cell (10 mm thickness) on a JASCO FP-6500 spectrometer. The light source was the xenon lamp (MAX 303 (irradiated at $420 \mathrm{~nm}$ through a bandpass filter), $300 \mathrm{~W}$; Asahi Spectra). CL was measured on a SPECTRARluor Plus luminometer.
Experimental Procedures and Characterization Data for the Synthesis of Each Caged Resveratrol. m-l-Caged Resveratrol (2) and p-l-Caged Resveratrol (3). Under the nitrogen atmosphere, resveratrol $1(229 \mathrm{mg}, 1.0 \mathrm{mmol})$ and pyridine $(80 \mu \mathrm{L}, 1.0 \mathrm{mmol})$ were stirred in tetrahydrofuran (THF) at $0{ }^{\circ} \mathrm{C}$ for $1 \mathrm{~h}$; then, chloroformate thiochromone $S, S$ dioxide $^{13}$ (110 $\left.\mathrm{mg}, 0.3 \mathrm{mmol}\right)$ in THF was added to the reaction mixture. After the mixture was stirred at $0{ }^{\circ} \mathrm{C}$ for $1 \mathrm{~h}$, the mixture was quenched with water. The reaction mixture was extracted with ethyl acetate, and the organic layer was washed with $\mathrm{H}_{2} \mathrm{O}$ and brine. Then, the collected organic layer was dried over $\mathrm{MgSO}_{4}$ and filtered through filter paper, and the solvent was evaporated. The residue was purified using silica-gel column chromatography (ethyl acetate/chloroform $=1: 9$ ) to afford the target compound 2 (17\% yield) as an orange solid and 3 (19\% yield) as a yellow solid.

(E)-(1,1-Dioxido-4-oxo-3-phenyl-4H-thiochromen-2yl)methyl (3-Hydroxy-5-(4-hydroxystyryl)phenyl) Carbonate (2). Orange crystal recrystallized from ethyl acetate and hexane. IR (KBr): 3451, 3032, 1768, 1735, 1671, 1606, 1589, $1514,1443,1386,1258,1159,1123,1081,1029 \mathrm{~cm}^{-1} .{ }^{1} \mathrm{H}$ NMR $\left(\mathrm{CDCl}_{3}, 500 \mathrm{MHz}, \delta\right): 8.76(\mathrm{~s}, 1 \mathrm{H}), 8.56(\mathrm{~s}, 1 \mathrm{H}), 8.22-8.17(\mathrm{~m}$, $2 \mathrm{H}), 8.11-8.08(\mathrm{~m}, 1 \mathrm{H}), 7.98-7.94(\mathrm{~m}, 1 \mathrm{H}), 7.54-7.52(\mathrm{~m}$, $3 \mathrm{H}), 7.49-7.44(\mathrm{~m}, 4 \mathrm{H}), 7.15-6.96(\mathrm{~m}, 2 \mathrm{H}), 6.93(\mathrm{t}, J=2 \mathrm{~Hz}$, $1 \mathrm{H}), 6.89(\mathrm{t}, J=2 \mathrm{~Hz}, 1 \mathrm{H}), 6.85-6.83(\mathrm{~m}, 1 \mathrm{H}), 6.57(\mathrm{t}, J=2 \mathrm{~Hz}$, $1 \mathrm{H}), 5.22(\mathrm{~s}, 2 \mathrm{H}) .{ }^{13} \mathrm{C}$ NMR (acetone- $d_{6}, 125 \mathrm{MHz}, \delta$ ): 179.24, 159.22 , 158.41, 153.40, 153.30, 145.67, 144.35, 141.62, 141.26, $135.95,134.42,132.45,130.54,130.28,130.20,130.03,129.51$, $129.47,129.03,128.97,125.42,123.73,116.40,111.81,110.61$, 107.96, 62.20. HRMS (ESI) calcd for $\mathrm{C}_{31} \mathrm{H}_{22} \mathrm{NaO}_{8} \mathrm{~S}(\mathrm{M}+\mathrm{Na})$ : 577.0933; found 577.0936.

(E)-4-(3,5-Dihydroxystyryl)phenyl ((1,1-Dioxido-4oxo-3-phenyl-4H-thiochromen-2-yl)methyl) Carbonate (3). Yellow solid. IR (KBr): 3443, 1767, 1667, 1595, 1507, 1443, 1374, 1306, 1220, 1160, 1074, $1010 \mathrm{~cm}^{-1} .{ }^{1} \mathrm{H}$ NMR $\left(\mathrm{CDCl}_{3}, 500 \mathrm{MHz}, \delta\right): 8.32(\mathrm{~s}, 2 \mathrm{H}), 8.21-8.17(\mathrm{~m}, 2 \mathrm{H}), 8.11-$ $8.08(\mathrm{~m}, 1 \mathrm{H}), 7.97-7.94(\mathrm{~m}, 1 \mathrm{H}), 7.63(\mathrm{~d}, J=8.5 \mathrm{~Hz}, 2 \mathrm{H})$, 7.54-7.52 (m, 3H), 7.49-7.47 (m, 2H), $7.20(\mathrm{~d}, J=8.5 \mathrm{~Hz}, 2 \mathrm{H})$, $7.14-7.06(\mathrm{~m}, 2 \mathrm{H}), 6.58(\mathrm{~d}, J=5 \mathrm{~Hz}, 2 \mathrm{H}), 6.31(\mathrm{~s}, 1 \mathrm{H}), 5.23(\mathrm{~s}$, $2 \mathrm{H}) .{ }^{13} \mathrm{C}$ NMR (acetone- $\left.d_{6}, 125 \mathrm{MHz}, \delta\right): 179.23,159.60$, $159.50,153.47,151.38,145.71,144.29,141.60,140.14,136.53$, $135.96,134.42,132.43,130.28,130.21,130.02,129.47,129.04$, $128.31,127.93,123.73,122.19,106.00,105.90,103.25,62.28$. HRMS (ESI) calcd for $\mathrm{C}_{31} \mathrm{H}_{22} \mathrm{NaO}_{8} \mathrm{~S}(\mathrm{M}+\mathrm{Na})$ : 577.09331; found 577.09311 . 
$m, p$-II-Caged Resveratrol (4). Under nitrogen atmosphere, compound $3(25 \mathrm{mg}, 0.045 \mathrm{mmol})$ and pyridine $(7 \mu \mathrm{L}, 0.09$ $\mathrm{mmol}$ ) were stirred in THF at $0{ }^{\circ} \mathrm{C}$ for $1 \mathrm{~h}$; then, chloroformate thiochromone $S, S$-dioxide $(17 \mathrm{mg}, 0.045 \mathrm{mmol}$ ) in THF was added to the reaction mixture. After the mixture was stirred at 0 ${ }^{\circ} \mathrm{C}$ for $1 \mathrm{~h}$, the mixture was quenched with water. The reaction mixture was extracted with ethyl acetate, and the organic layer was washed with $\mathrm{H}_{2} \mathrm{O}$ and brine. Then, the collected organic layer was dried over $\mathrm{MgSO}_{4}$ filtered through filter paper, and the solvent was evaporated. The residue was purified using silica-gel column chromatography (ethyl acetate/chloroform $=1: 9$ ) to afford target compound 4 (27\% yield) as a yellow solid.

(E)-4-(3-((( 1,1-Dioxido-4-oxo-3-phenyl-4H-thiochromen-2-yl)methoxy)(carbonyl)oxy)-5-hydroxystyryl)phenyl ((1,1-Dioxido-4-oxo-3-phenyl-4H-thiochromen2-yl)methyl) Carbonate (4). Yellow solid. IR (KBr): 3453, 3064, 3029, 2925, 2853, 1768, 1667, 1587, 1507, 1443, 1371, 1309, 1233, 1160, $1075 \mathrm{~cm}^{-1} .{ }^{1} \mathrm{H}$ NMR $\left(\mathrm{CDCl}_{3}, 500 \mathrm{MHz}, \delta\right)$ : $8.21(\mathrm{~d}, J=10 \mathrm{~Hz}, 2 \mathrm{H}), 8.15(\mathrm{~d}, J=9.5 \mathrm{~Hz}, 2 \mathrm{H}), 7.94-7.90(\mathrm{~m}$, 2H), 7.81-7.78 (m, 2H), 7.51-7.45 (m, 8H), 7.33-7.30 (m, $4 \mathrm{H}), 7.16(\mathrm{~d}, J=11 \mathrm{~Hz}, 2 \mathrm{H}), 7.03-6.83(\mathrm{~m}, 4 \mathrm{H}), 6.59(\mathrm{t}, J=2.5$ $\mathrm{Hz}, 1 \mathrm{H}), 5.22(\mathrm{~s}, 4 \mathrm{H}) .{ }^{13} \mathrm{C} \mathrm{NMR}\left(\mathrm{CDCl}_{3}, 125 \mathrm{MHz}, \delta\right): 178.46$, $156.79,152.92,152.81,152.13,150.65,145.07,145.05,143.81$, $143.75,140.63,140.61,139.79,139.56,135.18,135.03,134.90$, $134.70,133.53,133.41,130.74,130.72,130.03,129.20,129.15$, $129.10,129.04,128.75,128.55,128.47,128.00,127.81,127.71$, 123.37, 123.28, 121.36, 111.61, 111.44, 108.02, 61.67, 61.64 . HRMS (ESI) calcd for $\mathrm{C}_{48} \mathrm{H}_{32} \mathrm{NaO}_{13} \mathrm{~S}_{2}(\mathrm{M}+\mathrm{Na})$ : 903.1182; found 903.1188 .

III-Caged Resveratrol (5). Under nitrogen atmosphere, compound 1 (12 mg, $0.05 \mathrm{mmol})$ and pyridine $(40 \mu \mathrm{L}, 0.5$ mmol) were stirred in THF and $\mathrm{CH}_{2} \mathrm{Cl}_{2}(1: 1)$ at $0{ }^{\circ} \mathrm{C}$ for $1 \mathrm{~h}$; then, chloroformate thiochromone $S, S$-dioxide $(73 \mathrm{mg}, 0.2$ $\mathrm{mmol}$ ) in THF was added to the reaction mixture. After the mixture was stirred at $0{ }^{\circ} \mathrm{C}$ for $1 \mathrm{~h}$, the mixture was quenched with water. The reaction mixture was extracted with $\mathrm{CH}_{2} \mathrm{Cl}_{2}$, and the organic layer was washed with $\mathrm{H}_{2} \mathrm{O}$ and brine. Then, the collected organic layer was dried over $\mathrm{MgSO}_{4}$, filtered through filter paper, and the solvent was evaporated. The residue was purified using silica-gel column chromatography (ethyl acetate/ chloroform $=1: 9)$ to afford target compound 5 ( $33 \%$ yield $)$ as a yellow solid.

(E)-5-(4-((((1,1-Dioxido-4-oxo-3-phenyl-4H-thiochromen2-yl)methoxy)carbonyl)oxy)styryl)-1,3-phenylene Bis((1,1-dioxido-4-oxo-3-phenyl-4H-thiochromen-2-yl)methyl) Bis(carbonate) (5). Yellow solid. IR (KBr): 3064, 3028, 2926, $1769,1667,1587,1443,1371,1310,1218,1162,1073 \mathrm{~cm}^{-1} .{ }^{1} \mathrm{H}$ $\operatorname{NMR}\left(\mathrm{CDCl}_{3}, 500 \mathrm{MHz}, \delta\right): 8.21-8.20(\mathrm{~m}, 3 \mathrm{H}), 8.16-8.13(\mathrm{~m}$, $3 \mathrm{H}), 7.92-7.90(\mathrm{~m}, 3 \mathrm{H}), 7.81-7.78(\mathrm{~m}, 3 \mathrm{H}), 7.50-7.46(\mathrm{~m}$, $12 \mathrm{H}), 7.34-7.28(\mathrm{~m}, 7 \mathrm{H}), 7.23-7.20(\mathrm{~m}, 3 \mathrm{H}), 7.18-7.16(\mathrm{~m}$, 2H), 7.03-6.96 (m, 2H), $5.22(\mathrm{~s}, 2 \mathrm{H}), 5.20(\mathrm{~s}, 4 \mathrm{H}) .{ }^{13} \mathrm{C} \mathrm{NMR}$ $\left(\mathrm{CDCl}_{3}, 126 \mathrm{MHz}, \delta\right): 178.64,178.46,178.43,152.36,151.63$, $145.61,145.13,145.00,143.85,143.67,143.58,140.63,140.57$, $139.88,135.01,134.93,134.86,133.51,133.44,130.76,130.70$, $130.61,130.04,130.02,129.32,129.19,129.16,129.13,129.04$, 128.77, 128.74, 128.72, 127.94, 127.22, 123.38, 121.43, 116.93, 113.42, 61.62, 61.22. HRMS (ESI) calcd for $\mathrm{C}_{65} \mathrm{H}_{42} \mathrm{NaO}_{18} \mathrm{~S}_{3}(\mathrm{M}$ $+\mathrm{Na}$ ): 1229.143; found 1229.143 .

\section{PHOTODEPROTECTION PROCEDURE AND LUCIFERASE-INHIBITIVE ASSAY}

Photodeprotection of Each Caged Resveratrol (4 and 5) and FL Measurements. The photodeprotection of caged resveratrols was examined as follows. First, $\mathbf{4}$ or $\mathbf{5}$ were dissolved in DMSO to afford each $5 \mu \mathrm{M}$ solution. Next, each $5 \mu \mathrm{M}$ solution was irradiated by a xenon lamp (MAX 303; $420 \mathrm{~nm}, 300 \mathrm{~W}$ ) in a cuvette cell $(1 \mathrm{~cm})$. At each photoirradiation time, the FL intensity was measured using FL spectroscopy (JASCO FP-6500 spectrometer). After the photoirradiation, each photoirradiated solution was examined by the enzyme inhibitive assay as the next procedure.

Luciferase-Inhibitive Assay of Each Compound (Resveratrol (1), Caged Resveratrols (2-5), and Photoirradiated Caged Resveratrols). To a solution mixture containing $0.1 \mathrm{M}$ dithiothreitol $(1.0 \mu \mathrm{L}), 10 \mu \mathrm{M}$ ATP $(0.5$ $\mu \mathrm{L}), 5 \mathrm{mg} / \mathrm{mL}$ firefly luciferase $(0.025 \mu \mathrm{L}), 20 \times$ reaction buffer $(2.5 \mu \mathrm{L})$, and Ultrapure water $(35.975 \mu \mathrm{L})$ (using an ATP determination kit) in a 96-well white plate, $10 \mu \mathrm{L}$ of each compound solution $(5 \mu \mathrm{M})$ was added. Next, a $20 \mu \mathrm{M}$ luciferin solution $(50 \mu \mathrm{L})$ was added to each sample in a 96 -well white plate (the final concentration of caged resveratrol was $0.5 \mu \mathrm{M}$, containing $10 \%$ DMSO) for the luciferin-luciferase reaction. The plate was incubated at room temperature for $5 \mathrm{~min}$, and then CL was measured at $570 \mathrm{~nm}$ using a luminometer (SPECTRARluor Plus). In Figures 5 and 7, error bars indicate the standard deviation.

\section{ASSOCIATED CONTENT}

\section{Supporting Information}

The Supporting Information is available free of charge on the ACS Publications website at DOI: 10.1021/acsomega.7b00250.

NMR chart of synthesized compounds and ESI-MS spectrum and crystallographic data. CCDC: 1529573 (PDF)

\section{AUTHOR INFORMATION}

\section{Corresponding Authors}

*E-mail: y-west@ms.naist.jp (Y.N.).

*E-mail: kakiuchi@ms.naist.jp (K.K.).

ORCID

Yasuhiro Nishiyama: 0000-0001-7168-4217

Present Address

Department of Chemical Industry, Industrial Technology Center of Wakayama Prefecture (WINTEC), 60, Ogura, Wakayama 649-6261, Japan

\section{Notes}

The authors declare no competing financial interest.

\section{ACKNOWLEDGMENTS}

This work was supported in part by the JSPS KAKENHI Grant25560404, 15K12748, and 16K21170 and the NAIST Presidential Special Fund. We also thank Professors Masao Tanihara and Tsuyoshi Ando (the use of SPECTRARluor Plus luminometer), Yoshiko Nishikawa and Kazuo Fukuda (HRMS measurements), and Shohei Katao (X-ray crystallographic analysis) of NAIST. We appreciate Editage (www.editage.jp) for English language editing.

\section{REFERENCES}

(1) Rautio, J.; Kumpulainen, H.; Heimbach, T.; Oliyai, R.; Oh, D.; Järvinen, T.; Savolainen, J. Prodrugs: design and clinical applications. Nat. Rev. Drug Discovery 2008, 7, 255-270.

(2) Huttunen, K. M.; Raunio, H.; Rautio, J. Prodrugs-from serendipity to rational design. Pharmacol. Rev. 2011, 63, 750-751. 
(3) Klán, P.; Šolomek, T.; Bochet, C. G.; Blanc, A.; Givens, R.; Rubina, M.; Popik, V.; Kostikov, A.; Wirz, J. Photoremovable Protecting Groups in Chemistry and Biology: Reaction Mechanisms and Efficacy. Chem. Rev. 2013, 113, 119-191.

(4) Wang, P. Photolabile Protecting Groups: Structure and Reactivity. Asian J. Org. Chem. 2013, 2, 452-464.

(5) Mayer, G.; Heckel, A. Biologically active molecules with a "light switch". Angew. Chem., Int. Ed. 2006, 45, 4900-4921.

(6) Brieke, C.; Rohrbach, F.; Gottschalk, A.; Mayer, G.; Heckel, A. Light-controlled tools. Angew. Chem., Int. Ed. 2012, 51, 8446-8476.

(7) Skwarczynski, M.; Noguchi, M.; Hirota, S.; Sohma, Y.; Kimura, T.; Hayashi, Y.; Kiso, Y. Development of first photoresponsive prodrug of paclitaxel. Bioorg. Med. Chem. Lett. 2006, 16, 4492-4496.

(8) Noguchi, M.; Skwarczynski, M.; Prakash, H.; Hirota, S.; Kimura, T.; Hayashi, Y.; Kiso, Y. Development of novel water-soluble photocleavable protective group and its application for design of photoresponsive paclitaxel prodrugs. Bioorg. Med. Chem. 2008, 16, 5389-5397.

(9) Patchornik, A.; Amit, B.; Woodward, R. B. Photosensitive protecting groups. J. Am. Chem. Soc. 1970, 92, 6333-6335.

(10) Givens, R. S.; Matuszewski, B. Photochemistry of phosphate esters: an efficient method for the generation of electrophiles. J. Am. Chem. Soc. 1984, 106, 6860-6861.

(11) Klán, P.; Zabadal, M.; Heger, D. 2,5-Dimethylphenacyl as a New Photoreleasable Protecting Group for Carboxylic Acids. Org. Lett. 2000, 2, 1569-1571.

(12) Narumi, T.; Takano, H.; Ohashi, N.; Suzuki, A.; Furuta, T.; Tamamura, H. Isostere-Based Design of 8-Azacoumarin-Type Photolabile Protecting Groups: A Hydrophilicity-Increasing Strategy for Coumarin-4-ylmethyls. Org. Lett. 2014, 16, 1184-1187.

(13) Kitani, S.; Sugawara, K.; Tsutsumi, K.; Morimoto, T.; Kakiuchi, K. Synthesis and characterization of thiochromone $S, S$-dioxides as new photolabile protecting groups. Chem. Commun. 2008, 2103.

(14) Zhang, Y.; Tanimoto, H.; Nishiyama, Y.; Morimoto, T.; Kakiuchi, K. Novel Photolabile Protecting Group for Phosphate Compounds. Synlett 2012, 23, 367-370.

(15) Sugiura, R.; Kozaki, R.; Kitani, S.; Gosho, Y.; Tanimoto, H.; Nishiyama, Y.; Morimoto, T.; Kakiuchi, K. A novel thiochromone-type photolabile protecting group for carbonyl compounds. Tetrahedron 2013, 69, 3984-3990.

(16) Zhang, Y.; Zhang, H.; Ma, C.; Li, J.; Nishiyama, Y.; Tanimoto, H.; Morimoto, T.; Kakiuchi, K. Study of the Paternò-Büchi Type Photolabile Protecting Group and Application to Various Acids. Tetrahedron Lett. 2016, 57, 5179-5184.

(17) Sasaki, Y.; Sugiura, R.; Nishiyama, Y.; Tanimoto, H.; Morimoto, T.; Kakiuchi, K. Synthesis and evaluation of new caged compound with thiochromone derivative. Tetrahedron 2014, 70, 7973-7976.

(18) Hikage, S.; Sasaki, Y.; Hisai, T.; Tanimoto, H.; Morimoto, T.; Nishiyama, Y.; Kakiuchi, K. Synthesis of novel caged antisense oligonucleotides with fluorescence property. J. Photochem. Photobiol., A 2016, 331, 175-183.

(19) Bakhtiarova, A.; Taslimi, P.; Elliman, S. J.; Kosinski, P. A.; Hubbard, B.; Kavana, M.; Kemp, D. M. Resveratrol inhibits firefly luciferase. Biochem. Biophys. Res. Commun. 2006, 351, 481-484.

(20) Bernard, E.; Britz-McKibbin, P.; Gernigon, N. Resveratrol Photoisomerization: An Integrative Guided-Inquiry Experiment. J. Chem. Educ. 2007, 84, 1159-1161. 